\title{
Percepção dos atores sociais do turismo sobre o pulso de inundação do Pantanal (MT)
}

\section{Perception of the tourism social actors regarding the flood pulse of the Pantanal (MT, Brazil)}

\author{
Maiara Thaisa Oliveira Rabelo, Koen Antonius Johannes Arts, Pierre Girard, \\ Antonio Augusto Rossotto loris, Daniela Maimoni de Figueiredo
}

\section{RESUMO}

O Pantanal é a maior planície de inundação contínua do planeta. O ciclo periódico de seca e cheia, chamado de pulso de inundação, é o principal fator controlador do funcionamento e da manutenção da biodiversidade do Pantanal. Estas condições hidrobiológicas, aliadas à beleza cênica, são grandes atrativos à atividade turística na região. O objetivo deste trabalho foi analisar como os diferentes atores sociais do turismo (pousadeiros, turistas estrangeiros, turistas brasileiros, pescadores profissionais, agentes SEMA, guias de turismo, moradores locais) percebem o pulso de inundação e como este pode influenciar esta atividade no Pantanal de Poconé, um dos polos turísticos do Pantanal, considerando o expressivo crescimento da atividade nos últimos anos e a escassez de estudos na região. Foram previamente identificados sete principais grupos sociais, que posteriormente foram entrevistados em entrevista do tipo estruturada (37 entrevistas gravadas). Estas foram transcritas para a análise dos resultados e aplicado uma ferramenta de análise de texto para contagem das palavras mais mencionadas por cada grupo social. A grande maioria dos pousadeiros é de fazendeiros tradicionais que passaram a desenvolver serviços de hotelaria, atendendo basicamente turistas estrangeiros. Foram identificados conflitos entre pecuaristas e pousadeiros, relativo a onça pintada, que representa prejuízos ao rebanho e aos pousadeiros uma fonte de renda quanto ao turismo de "observação de onça"; e conflito entre a população nativa, tanto moradores locais quanto pescadores profissionais, que almejam por participarem mais diretamente no turismo e das instâncias de poder, concentrada nos pousadeiros e/ou pecuaristas. O pulso de inundação exerce forte influência sobre o aproveitamento turístico do Pantanal de Poconé, mas não foi nitidamente compreendido pelos diferentes grupos sociais do turismo, tanto quanto a percepção da importância do pulso na sua atividade quanto ao entendimento do conceito em si. Os grupos com melhor capacitação técnica (guias de turismo e agentes ambientais) e os moradores locais e pescadores profissionais, nativos da região, apresentaram melhor compreensão destes dois aspectos do pulso de inundação. O estudo apontou ainda a importância de se desenvolver um turismo com maior identidade local, que incluam outros atrativos, como as festas tradicionais da rica cultura de Poconé e a diversidade de ecossistemas aquáticos e terrestres na época de cheia.

PALAVRAS-CHAVE: Pesca; Socioambiental; Área Úmida. 


\section{ABSTRACT}

The Pantanal is the largest continuous floodplain on the planet. The periodic cycle of drought and flood, the so-called the flood pulse, is the controlling factor of the operation and maintenance of the Pantanal's biodiversity. These hydrobiological conditions, together with the scenic beauty, are great touristic attractions to the region. The objective of this work was to analyze how the different social actors of tourism perceive the pulse of flood and how it can influence the activity in the Pantanal of Poconé, one of the tourist centres of the Pantanal. The departing point of this research was the significant growth of activity in the last years and the scarcity of specific studies in the region. Seven main social groups were initially identified, which were later interviewed in a structured interview (37 recorded interviews in total). These were transcribed for the analysis of the results; the analytical tool Voyant tools was applied to count the main words mentioned by each social group. Results showed that the vast majority of the hostel owners are from traditional farmers who started to develop hotel services, catering mainly to foreign tourists. Conflicts between cattle ranchers and hostel owners were identified regarding the hunt of jaguars, in the form of losses to the herd against losses to the touristic activities based on "jaguar observation"; likewise, there are conflicts between the native population (professional fishermen and riverine), who seek to participate more directly in the tourism, and the business community in control of hostels and/or ranchers. The flood pulse exerts a strong influence on the tourist enjoyment of the Poconé Pantanal, but it was not clearly understood by the different social groups involved; the perception of the importance of the pulse is affected by the difficulty to understand the concept itself. The groups with better technical qualification (tourism guides and environmental agents) and the riverine and professional fishermen, natives of the region, showed a better understanding of these two aspects of the flood pulse. The study also revealed the importance of developing tourism with greater local identity, including other attractions, such as the traditional festivals of the rich culture of Poconé and the diversity of aquatic and terrestrial ecosystems during the flood season.

KEYWORDS: Fishing; Socioenvironmental; Wetland.

\section{Introdução}

As áreas úmidas estão entre os ecossistemas mais afetados por impactos humanos e ameaçados de destruição e no mundo. Por essa razão, vários tratados internacionais exigem o estabelecimento de inventários e medidas para a sua proteção (MILLENIUM ECOSYSTEM ASSESSMENT, 2005, DARWALL et al. 2008, SCBD, 2010).

A Convenção sobre Zonas Úmidas de Importância Internacional (Convenção Ramsar), tratado intergovernamental inicialmente estabelecida em 1971, na cidade iraniana de Ramsar, estabeleceu em 2010 um Memorando de Cooperação com a Organização Mundial do Turismo das Nações Unidas (OMT) como reconhecimento da interdependência existente entre o turismo sustentável e o manejo sustentável das zonas úmidas. Estas duas organizações estão desenvolvendo projetos conjuntos, sendo que os resultados obtidos até o momento demonstram benefícios práticos que 0 trabalho intersetorial oferece para alcançar a conservação das zonas úmidas. Graças às belezas cênicas e a exuberante biodiversidade, as áreas úmidas constituem uma parte fundamental da experiência turística e das 
viagens culturais em nível mundial. No Brasil, as áreas úmidas têm sido um dos principais destinos turísticos de milhares de viajantes ávidos por conhecer a riqueza ambiental e cultural que essas regiões abrigam (RAMSAR; UNWTO, 2012)

Enquanto área úmida, o Pantanal Mato-grossense é regido pelo seu principal fenômeno ecológico: o regime anual de cheia e seca (pulso de inundação), que regula a existência, a produtividade e a interação entre as espécies, aquáticas e terrestres, coabitantes do bioma pantaneiro, bem como as atividades humanas (RESENDE, 2008; WANTZEN et al. 2008).

As planícies de inundação são áreas que recebem periodicamente o aporte lateral das águas de rios, lagos, da precipitação direta ou de lençóis subterrâneos (JUNK, 1989; JUNK et al., 2014). As implicações decorrentes da regularidade do padrão de inundação e da sua duração são de importância ecológica, sendo de sua responsabilidade as modificações anuais do ambiente, determinando fases terrestre e aquática distintas (JUNK, 1997). Estas modificações anuais são o principal fator que rege a biodiversidade do Pantanal, pois ora favorece as espécies animais e vegetais relacionadas à fase de seca, ora favorece as espécies relacionadas à fase de cheia (JUNK et al., 1989). Além disso a inundação, de acordo com a intensidade e duração, é também um fator condicionante das diversas particularidades da vegetação da região (BRASIL, 1979).

As pesquisas efetuadas nos últimos 20 anos, por pesquisadores de diferentes áreas em vários países, têm demonstrado que o pulso de inundação é um processo ecológico chave a ser mantido para a manutenção e conservação da biodiversidade das planícies de inundação (GIRARD, 2011). Entretanto, poucas publicações consideram as interações do pulso de inundação com as comunidades tradicionais. Por exemplo, Pereira e Fabré (2009) avaliaram a territorialidade das comunidades da várzea amazônica, adaptadas às variações sazonais impostas pelo pulso de inundação, observando a relação custo-benefício da exploração pesqueira, madeireira e agrícola e sua relação com os conflitos socioambientais oriundos da exploração de recursos naturais de uso comum em áreas de livre acesso.

Sobre o Pantanal, Sato et al. (2013) mencionam que é um espaço onde as águas constroem novos territórios dispersos em distintas temporalidades e racionalidades. Seguindo o fluxo das águas, o Pantanal, conforme os autores é um espaço em constante movimento, tendo sua paisagem alterada entre épocas de seca e de cheia, habitada por povos que apresentam características peculiares de convívio com a dinâmica das águas.

Da Silva (1990) e Girard e Vargas (2008) mencionam que a conservação dos recursos naturais no Pantanal tem base cultural e econômica, sendo que "o homem pantaneiro (pescadores, fazendeiros, vaqueiros) adquiriu, por gerações, conhecimento ecológico empírico acerca dos saberes disseminados e perpetuados na comunidade, por compartilharem hábitos e valores da cultura local e participarem de uma história comum, submetendo-se às regras impostas pelo próprio ambiente" (GIRARD, 2012). 
Muito da economia local nas regiões de áreas úmidas advém diretamente do uso de recursos naturais. Peixes, produtos florestais ou mesmo a associação de gado em pastagens naturais de algumas regiões de áreas úmidas, como por exemplo, o Pantanal Mato-grossense, são primordiais para o modo de vida tradicional de subsistência de populações nativas e/ou ribeirinhas. As áreas úmidas também sustentam um potencial considerável para o turismo e atividades recreacionais (SERAFINI, 2007), como vêm ocorrendo expressivamente nos últimos anos no Pantanal.

Especificamente no Pantanal de Poconé, Fachim (2002) desenvolveu um trabalho de identificação e caracterização dos stakeholders da Estrada Parque Transpantaneira, no intuito de fomentar a elaboração do Plano de Manejo Participativo desta unidade de conservação Estadual, sendo que o turismo foi uma entre as vinte e duas categorias de stakeholders identificados pela autora.

Spaolense e Martins (2016) mencionam que "devem ser buscadas interações sustentáveis e ouvir a comunidade que será impactada pelas mudanças do ecoturismo, a inclusão social deve ser estabelecida com práticas e estratégias bem estudadas e planejadas para que os benefícios venham a ser atrativos para todos os atores sociais envolvidos".

O pulso de inundação rege tanto as condições naturais quanto as atividades humanas em planícies de inundação, incluindo o ecoturismo, que vem se desenvolvendo expressivamente no Pantanal nos últimos anos, onde são escassos os estudos sobre esta atividade. Neste sentido, o presente trabalho objetivou analisar a percepção dos atores do turismo sobre a influência que o pulso de inundação exerce sobre esta atividade no Pantanal de Poconé (Mato Grosso), preenchendo assim uma lacuna de conhecimento sobre esta atividade econômica e suas relações com os ciclos naturais de cheia e seca nesta planície de inundação. Para tanto utilizou uma ferramenta computadorizada de análise do discurso dos atores do turismo. A análise digital do texto está se estabelecendo nas ciências sociais desde a década de 90 e permite res-significar corpus de textos e compara-los (ALEXA, 1997; SINCLAIR; ROCKWELL, 2015).

\section{Material e Métodos}

\section{Área de Estudo}

Dentre as 12 regiões hidrográficas do Brasil definidas pela ANA (2017), a Região Hidrográfica do Paraguai, conhecida localmente como Bacia do Alto Paraguai (BAP), localizada entre os Estados de Mato Grosso e Mato Grosso do Sul, bem como em partes da Bolívia e Paraguai, possui uma área total $351.000 \mathrm{~km}^{2}$, sendo $71 \%$ localizados nestes Estados (JUNK et al., 2011). Esta região é dividida em três porções geomorfologicamente distintas: planalto, depressão e planície do Pantanal (FIGUEIREDO; SALOMÃO, 2008).

O Pantanal Mato-grossense está situado entre as coordenadas $16^{\circ}$ 20 S e 56-58 W (JUNK et al., 2011), na porção central da América do Sul, onde ocupa uma área de $139.558 \mathrm{~km}^{2}$. Esta planície não é homogênea, 
sendo dividida em 11 sub-regiões, de acordo com os padrões de inundação (intensidade e duração), relevo, solo e vegetação, dentre estas o Pantanal de Poconé, que corresponde a 10,1\% do Pantanal (SILVA; ABDON, 1998). Com uma área de $17.945 \mathrm{~km}^{2}$, o Pantanal de Poconé é cortado por duas rodovias não pavimentadas, Porto Cercado $(40 \mathrm{~km})$ e Transpantaneira (145 $\mathrm{km}$ ), ambas saindo da cidade de Poconé e terminando na margem direita do rio Cuiabá (Figura 1), ao longo das quais situam-se inúmeras pousadas que atendem a atividade turística nesta região.

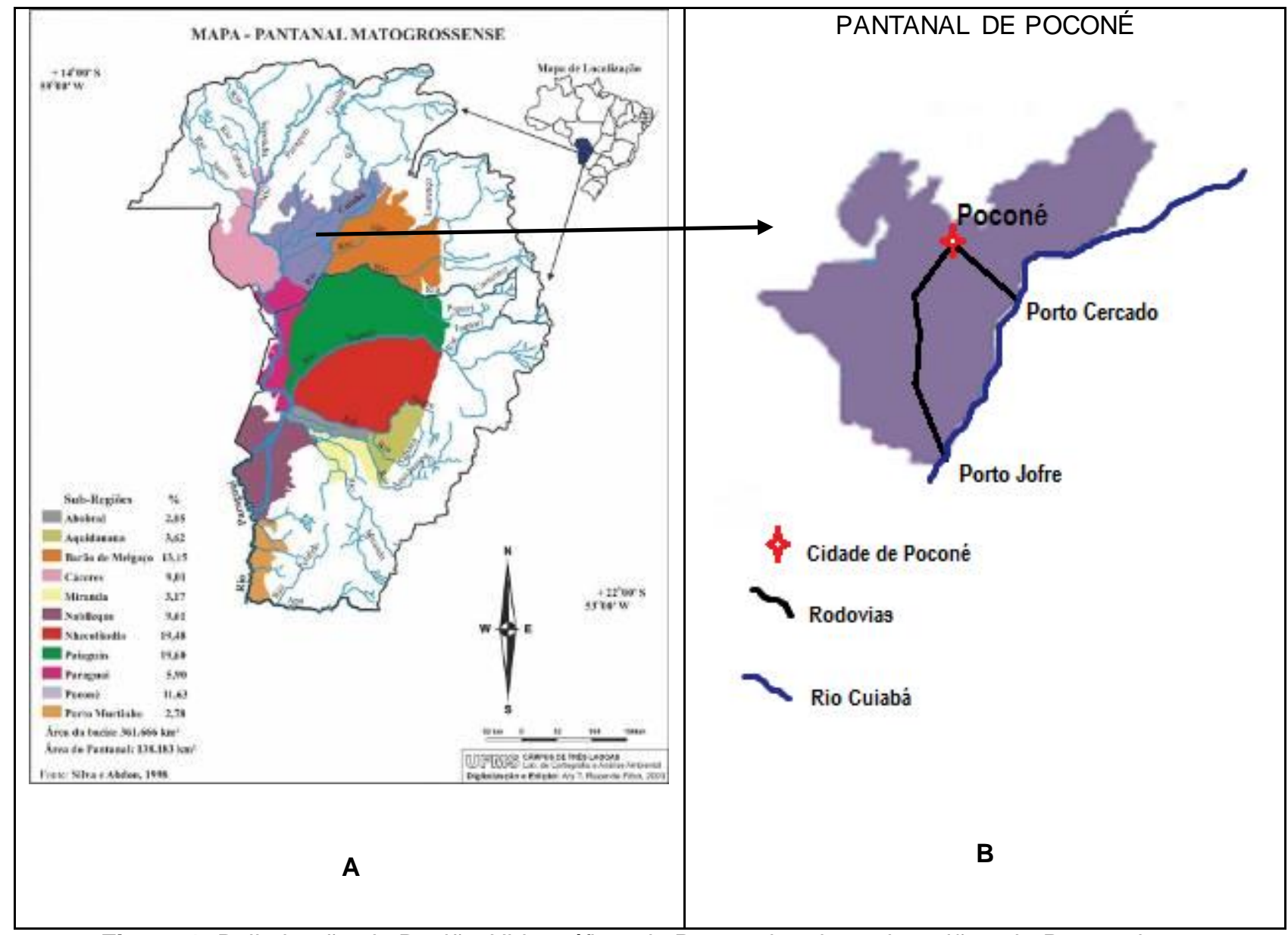

Figura 1: Delimitação da Região Hidrográfica do Paraguai e das sub-regiões do Pantanal Brasileiro, (A). Fonte: Silva e Abdon (1998) e detalhe do Pantanal de Poconé (B).

Figure 1: Delimitation of the Hydrographic Region of Paraguay and the subregions of the Brazilian Pantanal, (A). Source: Silva e Abdon (1998) and detail of the Pantanal of Poconé (B).

A temperatura média anual varia de 25,1-26,0 $\stackrel{\circ}{\mathrm{C}}$, com pluviosidade média de 1200-1400mm (TARIFA, 2011), sendo os meses mais secos entre maio e setembro e mais chuvosos entre outubro e abril. O pico da inundação na planície ocorre entre janeiro e março e deve-se, principalmente, a entrada de água dos rios da região do planalto e depressões.

Diversas unidades de paisagem ocorrem no Pantanal ao longo do gradiente de inundação, como baias, sangradouro, corixo, vazante, landi, brejo, campo, campina, murundum, dique marginal, cordilheira, capão, capão de aterro, entre outros, conceituados e descritos por Cunha e Junk 
(2011), sendo que todos estes citados acima ocorrem no Pantanal de Poconé.

As principais atividades econômicas do Pantanal de Poconé são a cria e recria de gado de corte, a pesca e o turismo. A pecuária extensiva foi iniciada há pelo menos 250 anos, constituindo-se na atividade econômica mais tradicional da região de Poconé (CAMPOS FILHO, 2002). Em meados dos anos 2000 houve na região uma migração no modelo de negócio dessas fazendas que passaram a atuar como pousadas rurais, oferecendo diversos tipos de passeios como: cavalgada pantaneira, passeios de barco, barco hotel, trilhas ecológicas, safari fotográfico, observação especifica de onças, focagem noturna de animais e city tour.

\section{Coleta e tratamento dos dados}

A primeira fase desta pesquisa, que tratou da identificação e caracterização dos grupos sociais, foi realizada com base em levantamento bibliográfico e conhecimento prévio da região, buscando a identificação dos atores sociais envolvidos com o turismo da área de estudo. Nesta fase foram listados os grupos sociais de acordo com sua atuação e envolvimento na atividade turística local, selecionados para a aplicação das entrevistas (Tabela1).

Tabela 1: Descrição dos atores sociais entrevistados que atuam na área de turismo do Pantanal de Poconé (MT).

Table 1: Description of the social actors interviewed who work in the tourism area of the Pantanal of Poconé, (MT, Brazil).

\begin{tabular}{|c|c|}
\hline Grupo social & Descrição \\
\hline Pousadeiros & $\begin{array}{l}\text { Autodenominação de proprietários e responsáveis por empreendimentos } \\
\text { de hospedagem ao longo das estradas Parques Transpantaneira e Porto } \\
\text { Cercado no município de Poconé. }\end{array}$ \\
\hline $\begin{array}{c}\text { Turistas } \\
\text { Estrangeiros }\end{array}$ & $\begin{array}{l}\text { Pessoas que se deslocam de outros países para o Pantanal de Poconé } \\
\text { com a finalidade de passar momentos de lazer, conhecer a cultura local } \\
\text { e/ou conhecer as belezas cênicas e riquezas de fauna e flora local que } \\
\text { são ausentes na região da residência habitual. }\end{array}$ \\
\hline $\begin{array}{c}\text { Turistas } \\
\text { Brasileiros }\end{array}$ & $\begin{array}{l}\text { Pessoas que se deslocam de outras regiões do Brasil para o Pantanal } \\
\text { de Poconé com a finalidade de passar momentos de lazer, conhecer a } \\
\text { cultura local e/ou conhecer as belezas cênicas e riquezas de fauna e } \\
\text { flora local que são ausentes na região da residência habitual. }\end{array}$ \\
\hline $\begin{array}{l}\text { Pescadores } \\
\text { profissionais }\end{array}$ & $\begin{array}{l}\text { Pescadores profissionais nativos que comercializam o pescado em } \\
\text { feiras e comércios locais. }\end{array}$ \\
\hline $\begin{array}{c}\text { Moradores locais } \\
\text { nativos }\end{array}$ & $\begin{array}{l}\text { São residentes nas proximidades das áreas de estudo, trabalhadores } \\
\text { das pousadas visitadas, ativistas da cultura local e também podem } \\
\text { praticar atividades extrativistas, porém não são pescadores } \\
\text { profissionais. }\end{array}$ \\
\hline Guias de turismo & $\begin{array}{l}\text { Atuam no acompanhamento de grupos de turistas nacionais ou } \\
\text { internacionais, nos mais diferentes tipos de passeios oferecidos na } \\
\text { região, prestando informações sobre as manifestações culturais e } \\
\text { geográficas locais, como também na assistência ao turista durante a } \\
\text { viagem. }\end{array}$ \\
\hline $\begin{array}{l}\text { Agentes de } \\
\text { segurança } \\
\text { ambiental (SEMA) }\end{array}$ & $\begin{array}{l}\text { Servidores públicos da Secretaria Estadual de Meio Ambiente (SEMA - } \\
\text { MT) responsáveis por coordenadorias que atuem na regulamentação e } \\
\text { fiscalização das atividades ligadas ao turismo na região do Pantanal } \\
\text { Norte de Mato Grosso. }\end{array}$ \\
\hline
\end{tabular}


Seguindo a metodologia proposta por Marconi e Lakatos (2012), foi adotado o tipo de entrevista 'padronizada ou estruturada', aquela em que o entrevistador segue um roteiro previamente estabelecido. Neste trabalho, as perguntas feitas aos entrevistados foram predeterminadas, realizadas de acordo com um formulário elaborado previamente e direcionado para cada grupo social identificado. Esta abordagem buscou, na transcrição e compilação posterior das respostas, que todos os produtos fossem comparados com o mesmo conjunto de perguntas, onde as discrepâncias devem refletir diferenças entre os respondentes e não diferenças nas perguntas (LODI, 1974). As entrevistas foram aplicadas no mês de setembro de 2015, por dez dias consecutivos. Cabe ressaltar que este mês abrange o período de seca e, portanto, alta temporada para o turismo local. Das 22 pousadas catalogadas ao longo das rodovias, dez participaram desta pesquisa (Tabela 2).

Tabela 2: Entrevistados por grupo de atores envolvidos na atividade turística do Pantanal de Poconé (MT).

Table 2: Interviewees by group of actors involved in the tourism activity of the Pantanal of Poconé (MT, Brazil).

\begin{tabular}{cccc}
\hline Grupos sociais & Homens & Mulheres & Total \\
\hline Pousadeiros & 8 & 2 & 10 \\
Turistas estrangeiros & 3 & 2 & 5 \\
Turistas Brasileiros & 4 & 1 & 5 \\
Pescadores profissionais & 6 & 0 & 6 \\
Agentes SEMA & 3 & 1 & 4 \\
Guias de turismo & 3 & 1 & 4 \\
Moradores locais & 2 & 1 & 3 \\
TOTAL & 29 & 8 & 37 \\
\hline
\end{tabular}

Em outubro de 2015, foram realizadas quatro (4) entrevistas na Secretaria Estadual de Meio Ambiente (SEMA), por desenvolver suas atividades na área de estudo, mas possuir sede em Cuiabá, com agentes das coordenadorias que atuam nas áreas ligadas ao turismo (Tabela 2). Este grupo foi identificado por sua atuação junto ao planejamento, gestão e regulação dos recursos explorados pela atividade turística, principalmente no que diz respeito à pesca, devido ao elevado número de turistas interessados nessa modalidade.

Posteriormente, foi realizada a avaliação das trinta e sete entrevistas realizadas na primeira fase. A compilação de dados contou com a transcrição integral das gravações, organizando as informações e discussões por grupo social. Estas representações foram agrupadas em categorias de atividade econômica e institucional desenvolvidas pelos mesmos.

Para tratar os dados coletados através das entrevistas foi utilizado o Voyant Tools (SINCLAIR; ROCKWELL, 2012) que é um aplicativo de código aberto e gratuito que permite trabalhar com os seus próprios textos ou coleções de texto existentes para executar funções básicas de mineração de palavras (http://voyant-tools.org/). Estas funções permitem extrair 
rapidamente características comuns entre os diferentes atores sociais entrevistados e identificar quais foram às palavras mais ditas por cada um. A transcrição integral do conteúdo de todas as entrevistas foi inserida no programa, buscando destacar as palavras mais utilizadas e os temas em comum mais enfatizados. Na sequência foram inseridas as entrevistas filtradas por grupo social, apontando quantas vezes determinado grupo citou cada palavra, indicando seus principais interesses e preocupações. As 25 palavras mais citadas por todos os grupos sociais foram comparadas com as 25 mais citadas individualmente, por cada grupo social. Nesta comparação surgiram 15 palavras presentes em todas as listas, gerando um ranking com os termos mais citados por todos os grupos e comparados quanto à quantidade de vezes mencionados individualmente em cada grupo.

Para o termo pulso de inundação, foi avaliado ainda qual a real importância para cada grupo comparando com a percepção que cada grupo teve e qual a conhecimento que cada grupo apresentou sobre este termo em relação à importância percebida, baseado nos dados das entrevistas filtradas pelo aplicativo Voyant tools.

\section{Resultados e discussão}

Os resultados das 37 entrevistas com os sete atores sociais do turismo no Pantanal de Poconé, identificados previamente, são apresentados a seguir.

\section{Pousadeiros}

Entre os dez empresários entrevistados, pode-se observar que a grande maioria (97\%) é de fazendeiros tradicionais que passaram a desenvolver serviços de hotelaria, devido ao crescimento da atividade turística nos últimos dez/quinze anos na região e à decadência da atividade pecuária. Ao longo da estrada Transpantaneira, apenas uma fazenda foi adquirida recentemente por um empresário espanhol e outra por uma grande rede hoteleira, todas as demais estão nas fazendas de herança da própria família que desempenha a função.

Das pousadas situadas na Transpantaneira, 99\% dos hóspedes que recebem ao longo do ano é composto por turistas estrangeiros, dentre os quais, os proprietários ressaltaram como mais frequentes alemães, holandeses e suíços. Nos últimos dois anos, porém, notou-se aumento no número de brasileiros, principalmente das regiões sul e sudeste. Apontam ainda que nos meses de julho a setembro a demanda é essencialmente de estrangeiros e de dezembro a março de brasileiros. Entretanto, $70 \%$ dos empresários disseram que não estão disponíveis para receber turistas nos meses de cheia, independente da procura. As justificativas são as mais variadas: na época da cheia as aves e animais terrestres, principais atrativos dos turistas, se dispersam na planície de inundação, dificultando a visualização, mosquitos em demasia e dificuldade de acesso, já que a entrada de algumas pousadas está em áreas alagáveis. 
Dentre todos os empreendimentos visitados, apenas um empresário está investindo na divulgação das paisagens pantaneiras em épocas de cheia. Ele conta que há cerca de um ano vem divulgando em feiras e eventos internacionais de turismo a diferença entre o mesmo ambiente durante 0 ano, o que tem garantido a sustentabilidade da atividade em ambos as épocas do ano, mantendo a pousada funcionando e com hóspede em praticamente todos os meses.

Dos entrevistados, 60\% julgaram-se incapazes de diferenciar o Pantanal de Poconé de outras regiões da planície de inundação, por desconhecer os demais tipos de pantanais, porém os outros $40 \%$ responderam que distinguem e destacaram as diferenças quanto a localização, mencionando que o Pantanal de Poconé está na porção mais baixa e, portanto, é inundado primeiro que as demais regiões, mas seca depois delas.

No entanto, estudos realizados por Franco e Pinheiro (1982 apud REBELLATO, 2010) demonstraram que o Pantanal Norte, onde se localiza a região de Poconé, apresenta extensa faixa com fraca inundação, onde as cotas altimétricas excedem 130 metros. Em direção ao sul as áreas são bastante inundadas, pois as cotas altimétricas decrescem para 110-100 m. Isto indica que os pousadeiros desconhecem o padrão de inundação do Pantanal de Poconé em relação às outras regiões da planície.

No âmbito social, os pousadeiros afirmaram que as diferenças entre os atores do turismo se dão por conta da colonização, visto que a região da Transpantaneira é até hoje habitada, em sua maioria, por familias tradicionais pantaneiras, com vasta experiência sobre a região e sua sazonalidade habitual. Essas afirmações indicam, mais uma vez, que estes empresários têm pouco conhecimento sobre a diversidade ambiental e social da área total do Pantanal, ou seja, outras regiões além do município de Poconé, e sentem-se os únicos habitantes experientes e adaptados ao pulso de inundação. De acordo com a Coordenação das Comunidades Tradicionais do Pantanal (CCTP) (2013), todas as regiões do Pantanal são habitadas por ribeirinhos fortemente identificados com seu território e ávidos por valorizar seu ambiente natural. Cada região apresenta singularidades próprias de sua colonização, mas mantém arraigadas suas tradições culturais.

Das pousadas, $70 \%$ apresentaram desenvolvimento semelhante ao longo do tempo. Tratam-se de pecuaristas tradicionais que, pelo aumento da atividade turística de apreciação da natureza, perceberam uma oportunidade de negócio rentável e de baixo investimento, pois o público estrangeiro prefere hospedagem de modelo rústico, sem muito conforto, de modo a sentir-se mais próximo do cotidiano do homem pantaneiro e da vida animal selvagem.

Todos os pousadeiros entrevistados (100\%) reconhecem a influência do pulso de inundação sobre sua atividade, seja no modelo de negócio, no perfil do turista, demanda de serviço ou até mesmo pela inatividade temporária nos meses de cheia, mas não possuem familiaridade com 0 termo pulso de inundação, que precisou ser conceituado durante a 
entrevista. Porém, demonstraram percepção dos ciclos naturais aos quais estão sujeitos o Pantanal, além da adaptação da atividade a estes ciclos.

Em relação as alterações no pulso de inundação nos últimos anos, todos os pousadeiros afirmaram notar diferenças anuais. $70 \%$ citaram que houve grande mudança nos últimos 20 anos, indicando como causa desta alteração a construção da usina hidrelétrica de Manso e mencionando que a cada ano o pulso tem sido diferente, principalmente, na intensidade das cheias, que estão menos intensas, ou seja, áreas que em anos anteriores eram alagadas, hoje permanecem secas durante todo o ano.

Girard (2011) comenta que as represas têm a capacidade de alterar o fluxo ou até o regime das cheias dependendo de seu tamanho, tipo e também de números. Os trabalhos da Comissão Mundial de Represas (World Commission on Dams) não deixam dúvidas sobre isso (WCD 2000). No entanto, há escassez de estudos conclusivos sobre impactos da Usina Hidrelétrica de Manso sobre o pulso de inundação do Pantanal de Poconé, o que não permite afirmar que esta usina, que foi projetada para atender ao conceito de usos múltiplos do reservatório e da água, seja a principal causa das mudanças nos padrões de inundação, como mencionam os pousadeiros, podendo ter outras causas antrópicas ou mesmo fatores da dinâmica natural interanual comum em planícies de inundação (SOUZA et al., 2009; GIRARD, 2002).

Dos empresários entrevistados, 60\% apontaram como ator mais importante atualmente no Pantanal eles próprios, por serem diretamente interessados na preservação e conservação dos recursos naturais. $20 \%$ apontam ainda os fazendeiros locais da pecuária extensiva como os tomadores de decisão mais relevantes da região. 10\% destacam a fauna da região como principal ator do Pantanal atualmente, mencionando que a natureza é fonte de renda para o local. Tal observação tem relação direta com a emergente literatura acadêmica que enfatiza a agência histórica da natureza. Os demais 10\% não souberam ou não opinaram. Estes índices denotam que o poder econômico local, que antes era dos pecuaristas, está migrando para a atividade turística, sem qualquer alteração no grupo de poder. Isso pode ser interpretado como um fator de concentração de renda e de monopólio dos recursos naturais disponíveis ao turismo, não permitindo que outras atividades ou outros grupos de poder desfrutem dos mesmos privilégios. Dos que mencionaram a fauna como ator mais importante, percebe-se que não compreendem o conceito de grupo com poder e tomador de decisão numa região, mas, por outro lado, valorizam um aspecto fundamental do turismo na região.

Quanto a existência de conflitos entre os pousadeiros e demais grupos vinculados ao turismo, $70 \%$ deles disseram não haver conflitos entre as partes, porém destacam que também não há nenhum tipo de cooperação. Em contrapartida, 30\% afirmou haver um pequeno conflito entre fazendeiros e pousadeiros quanto às onças-pintadas, que quando atacam o gado são abatidas, prejudicando a disponibilidade dos animais para apreciação dos turistas. 
Quando perguntados sobre as principais ameaças ao Pantanal e se as mesmas afetam as pousadas, $30 \%$ disseram que é a pesca predatória, $20 \%$ desmatamento, $10 \%$ citaram queimadas como a questão mais ameaçadora e $40 \%$ não souberam responder. A alta porcentagem indicando a pesca como principal ameaça ao Pantanal pode contradizer a afirmação dos empresários sobre não haver nenhum tipo de conflito entre as partes, uma vez que o turismo de pesca é um dos segmentos mais fortes na região, atraindo anualmente milhares de pescadores amadores. Contudo, os responsáveis pelas pousadas especializadas no turismo de pesca alegam incentivar a pesca esportiva, ou seja, o pescador retira o pescado do rio por instantes, apenas para medir e fotografar, e em seguida retorna o peixe vivo ao seu habitat.

Quando questionados se as ameaças estão sendo tratadas adequadamente na região, $98 \%$ dos pousadeiros afirmam que não há tratamento algum, visto que o posto de fiscalização situado na estrada Transpantaneira estava desativado desde janeiro de 2013 e até a finalização deste estudo em setembro de 2015, e as campanhas são ineficientes diante da demanda. Os outros $2 \%$ salientam que a consciência geral dos usuários tem despertado para a conservação destes recursos, minimizando assim impactos frequentes no passado. Essas afirmações sugerem que o setor empresarial local tem severas críticas quanto a atuação do poder público diante de suas demandas. Os pousadeiros reiteraram que buscam ajuda dos órgãos ambientais através da Associação de Hotéis, Pousadas e Restaurantes de Poconé, além de assegurar que apoiam todas as campanhas realizadas pela Secretaria Estadual de Meio Ambiente com o que for possível entre infraestrutura e informações. Nenhum deles reconheceu sua atividade como ameaça potencial ao meio ambiente pantaneiro.

Todos os empresários afirmaram que a atividade turística é extremamente benéfica para a conservação do ambiente, mesmo aqueles mais focados no turismo de pesca, e mencionam que a manutenção dos recursos naturais está diretamente ligada à garantia futura desta atividade econômica. Neiman (2012) aponta que o ecoturismo de contemplação é mesmo benéfico do ponto de vista da preservação do ambiente, já que seu desenvolvimento futuro depende única e exclusivamente da manutenção de suas paisagens. Porém o autor aponta que modelos de turismo de pesca necessitam de muita atenção tanto por parte dos empresários do setor quanto das autoridades competentes, para que sejam cumpridas as leis de proteção ao recurso. Os pousadeiros entrevistados acreditam que é possível que a atividade cresça e se desenvolva ainda mais, com maior procura e interesse por parte dos turistas, pois este modelo de ecoturismo, turismo de apreciação, pesca esportiva e observação de pássaros é tendência mundial no seguimento. Apenas salientam que, para ajudar, poderia haver maior divulgação por parte do governo nacional, ou seja, mais uma vez, creditam a responsabilidade ao poder público.

A caça, por sua vez, foi apontada como inexistente pelos entrevistados devido ao aumento no interesse do turismo de apreciação de onças na região do Porto Jofre. Porém, alguns citaram que é de 
conhecimento geral que entre os fazendeiros pecuaristas da região ainda há matança de onças quando estas atacam seu rebanho. Brito et al e Harris et al (2005) afirmam que os conflitos entre o turismo e a pecuária existem, ainda que em menor número que no passado, pelo interesse sobre a onçapintada e a parda, que são perseguidas por produtores rurais devido à predação ao gado. Sobre a perturbação animal, os pousadeiros negam recorrer a ceva para atrair animais, especialmente a onça-pintada, para facilitar seu encontro nos passeios oferecidos aos turistas, porém novamente afirmam saber de casos isolados com conduta contrária e ilegal.

\section{Turistas Estrangeiros}

Foram entrevistados cinco turistas estrangeiros de nacionalidades: alemã, australiana e suíça, interessados em conhecer um bioma de extrema variedade biológica e completamente diferente dos que estão habituados em seus países de origem.

A resposta sobre como o turista descreveria o Pantanal foi unânime quanto ao destaque que deram a magnitude da biodiversidade presente no local e sua beleza cênica surpreendente. Todos afirmaram ter tido todas as expectativas atingidas na viagem. Dos três entrevistados, um assegurou que teve sua expectativa superada do ponto de vista da quantidade de animais observados, variedade de passeios e recepção das pessoas.

Os turistas entrevistados não vieram à procura de um tipo de animal especifico, mas sim contemplação da natureza em geral. Esta pergunta foi elaborada considerando que muitos turistas estrangeiro pertencem a grupos amadores de observadores de aves, como mencionado por um pousadeiro, que destaca este grupo como frequente na região.

Os turistas apontaram que estão interessados com o contato direto com a natureza, não se incomodam com o calor excessivo, insetos e nem consideram primordial que a pousada que os recebe ofereça infraestrutura de lazer artificial, como por exemplo, piscina. Tampouco se preocupam com o desgaste físico causado pelos passeios realizados.

Todos afirmaram conhecer a sazonalidade das épocas de cheia e seca do Pantanal, ou seja, do pulso de inundação, pois buscaram informações prévias sobre o local ou foram informados pelos guias de turismo durante os passeios.

\section{Turistas brasileiros}

Dentro deste grupo de interesse foram identificados dois perfis distintos. O primeiro grupo busca principalmente conforto e relaxamento em sua viagem. Responderam que dão preferência a hotéis que possuam infraestrutura de lazer artificial como piscina, playground e demais recursos, afinal viajam com a familia, frequentemente com crianças, e preferem atividades mais leves e menos exaustivas. Este nicho está concentrado na hospedagem da rodovia Porto Cercado (hotel de grande porte) e em apenas uma pousada situada na Transpantaneira, filial de uma grande rede hoteleira. Procuram por passeios com guias disponibilizados pelo hotel, 
como safari de observação animal em carro aberto ou barco para contemplação da natureza e das paisagens locais. Permanecem, geralmente, por um fim de semana, feriado ou passam o dia nas pousadas que oferecem day use. Descreveram o Pantanal destacando a biodiversidade, utilizando como referência o que veem na internet, televisão e outros meios de comunicação. Afirmaram não ter conhecimento prévio quanto a dimensão da mudança que ocorre na paisagem nas épocas de cheia e seca, surpreendendo-se ao ver fotos, filmes e animações desta transformação exibidas no hotel. Garantem que tiveram suas expectativas superadas, principalmente na quantidade de animais avistados.

Um público bastante diferente, ainda que brasileiro, foi identificado nas pousadas da região de Porto Jofre e nos barcos hotéis que tem como partida Porto Cercado, trata-se do turismo específico de pesca, que é composto, em sua maioria, por empresários do sexo masculino, de poder aquisitivo elevado, interessados na pesca esportiva. Para esse subgrupo o conforto e o modelo spá das acomodações do hotel não se fazem essenciais. Afirmam que estão interessados na diversidade de espécies, quantidade disponível e tamanho exacerbado do pescado dos rios do Pantanal. Descrevem o ambiente baseado nesta premissa de abundância e não consideram esta atividade, de modo algum, danosa ao equilíbrio do ecossistema. Afirmam ter conhecimento sobre o pulso de inundação e as modificações por ele causadas, apesar de não frequentarem a região durante todo o período de cheia (apenas no final da cheia, em março), por coincidir com o período de piracema, quando a pesca é proibida. Nos meses de seca, temporada livre para pesca, chegam a ficar até 15 dias no Pantanal, hospedados diretamente nos barcos hotéis navegando pelo rio Cuiabá ou nos hotéis a margem do rio para onde retornam somente ao fim do dia, depois de exercerem a pesca esportiva embarcados em lanchas ou outros tipos de embarcações. Este cenário ocorre em três locais específicos do Pantanal de Poconé: o hotel de Porto Cercado nas margens do Rio Cuiabá, nas margens do Rio Pixaim (aproximadamente no meio da Transpantaneira) e no final da Transpantaneira, em Porto Jofre. Estes locais são propícios ao turismo de pesca, uma vez que o período de permissão para esta atividade inclui parte da época de cheia, quando pescadores amadores, em sua maioria, frequentam o Pantanal e usufruem de seus serviços ambientais e de turismo.

Os turistas brasileiros de pesca, assim como os pousadeiros entrevistados, afirmaram que esta modalidade de turismo não está baseada na retirada do recurso pesqueiro do rio, sequer ao transporte do mesmo às localidades de origem, mas sim no prazer de apreciar o passeio de barco, admirar as medidas e fotografar o peixe e devolve-lo em seguida ao seu habitat. Entretanto, Sudré (2012) afirma que no rio Paraguai em Cáceres, região do Pantanal com amplo desenvolvimento desse mesmo modelo de turismo, é comum se observar o processo de desembarque dos barcoshotéis no cais e o que chama atenção é a quantidade de peixes abatidos. Com relação ao pesque-e-solte, Chaves e Freire (2012) mencionam que no Brasil há falta de conhecimento de atributos quali-quantitativos, da reação das espécies nativas ao trauma experimentado, e do exato amparo legal 
nesta prática, que não deve ser vista como uma panaceia ou adotada como medida de gestão aplicável a quaisquer condições. Os autores citam vários estudos que apontam para a mortalidade de peixes após a soltura, por vários fatores que não a asfixia fora da água, que é um dos únicos danos reconhecidos como risco de morte aos peixes por aqueles que praticam esta modalidade pesqueira.

Moraes (2002) entrevistou 220 pescadores esportivos no Pantanal de Mato Grosso do Sul, ao longo de uma Estrada Parque similar às rodovias Transpantaneira de Poconé, sendo que 95\% foram respondidos por homens brasileiros que vivem fora do Pantanal. Enquanto aspectos diretos da pesca esportiva (capturar grandes peixes, uma variedade de peixes ou muitos peixes) foram as razões mais importantes para cerca de $36 \%$ dos pescadores, praticamente a metade citou razões associadas com o turismo ao ar livre de natureza mais geral sendo que, aproximadamente, 38\% dos pescadores indicaram que sua principal razão para visitar o Pantanal foi a qualidade do ambiente natural e $11 \%$ citaram a possibilidade de ver e observar a vida silvestre como sua motivação principal, com isso o autor comenta que se os pescadores esportivos não estão motivados somente pela captura de peixes, mas também para contemplar o ambiente natural único do Pantanal. Menciona ainda que o objetivo da administração pesqueira não deve ser, necessariamente, produzir mais peixes para a pesca esportiva, mas sim reorientar seus investimentos e suas atividades para proporcionar os serviços que os visitantes estão interessados em comprar, oferecendo alternativas e experiências para turistas voltados à natureza.

\section{Pescadores profissionais}

Os seis pescadores entrevistados são nascidos na região, composto por profissionais que comercializam o pescado em feiras e no comércio local. Para esse conjunto social, a percepção do pulso de inundação na região está fortemente ligada ao período de pesca livre e piracema, bem como sua descrição do ecossistema também está vinculada a abundância de recursos pesqueiros e hídricos. Constatou-se que todos os pescadores profissionais entrevistados reconhecem a diminuição na quantidade de pescado disponível nos rios ano a ano. Já entre os amadores (subgrupo dos turistas brasileiros) essa percepção foi nula, pois referiram-se aos recursos pesqueiros como se fossem infindáveis.

Entre as ameaças ao Pantanal, 40\% dos pescadores afirmaram que temem o aumento do número de barragens para construção de hidrelétricas na parte alta da bacia, também mencionado pelos pousadeiros, os demais citaram o avanço da agricultura nas áreas de drenagem dos rios do planalto, temendo a contaminação das águas por defensivos agrícolas. Quando questionados sobre o futuro da atividade turística na região, os pescadores ressaltam a necessidade de uma reestruturação do setor, visando à descentralização da renda advinda do turismo e o maior envolvimento da comunidade na atividade, gerando emprego, renda e desenvolvimento para o local. Estas respostas corroboram com o citado pela maioria dos 
pousadeiros, que apontaram como ator mais importante atualmente no Pantanal eles próprios. Os pescadores citaram ainda que, dado seu ofício, sentem-se mais pressionados pela fiscalização do órgão ambiental do que os turistas e pousadeiros, corroborando com o explicitado por Sudré (2012), que aponta as atividades pesqueiras como geradoras de impactos sociais, culturais e ambientais, resultantes de uma forma desordenada da atividade, trazendo em si conflitos, seja ele entre o pescador profissional e o amador (esportivo) ou entre as Leis Federais e Estaduais de Pesca, Conselho Municipal de Meio Ambiente e o setor do turismo.

Sato et al. (2013) identificaram diferentes grupos sociais em Mato Grosso, baseado em cinco dimensões, entre elas a Local da Cultura e Habitat, na qual se inserem grupos com identidades que se fazem na ligação com o local, onde a cultura se manifesta. Estes são intrinsecamente ligados aos territórios e, ainda dependentes do habitat, possuindo forte sentido de pertencimento ao local onde vivem, no qual os autores incluem dois grupos denominados povos pantaneiros e ribeirinhos. Os pescadores profissionais nativos do presente trabalho podem ser incluídos no grupo povos ribeirinhos, cuja atividade predominante é a pesca, apoiada pela agricultura de subsistência. Os autores comentam que suas expressões de vida se organizam nas dinâmicas das cheias e das vazantes, tendo maior identificação com a água do que com a terra. Os principais conflitos socioambientais enfrentados por estes povos estão relacionados com o acesso aos produtos pesqueiros, de forma peculiar, pela invasão dos pescadores externos, impulsionados pelo turismo de pesca e as mudanças que vem ocorrendo, como o aumento da seca nas estiagens e a falta de peixes nos rios, devido à sobre pesca. De maneira geral, o aumento na dificuldade de acesso ao pescado é o conflito eminente enfrentado por este grupo, mas cujas causas apontadas nem sempre foram as mesmas da presente pesquisa, devido a abordagem e métodos diferentes.

\section{Moradores locais nativos}

A população nativa pantaneira demonstrou ter muito conhecimento sobre a dinâmica hidrológica a qual é submetido o Pantanal anualmente pois, quando indagados sobre o pulso de inundação, todos descreveram a variação sazonal das águas baseado em suas experiências e percepções. Afirmaram que o pulso de inundação tem se alterado ano a ano, principalmente no que diz respeito a intensidade e duração das cheias, que tem sido menores a cada ano, como também apontado pelos pousadeiros. Da Silva (1995) corrobora com os dados obtidos na presente pesquisa quando afirma que os pantaneiros reconhecem a importância do regime de cheias e do ritmo das águas para a renovação da vida no Pantanal e para a preservação de seus ecossistemas.

A atividade turística é vista pelos moradores como uma das maiores oportunidades para o desenvolvimento econômico futuro da região, porém apontam que devem ocorrer melhoras na distribuição da renda gerada pela atividade por toda a população e, principalmente, para o município de Poconé e sua área urbana, visto que, além dos atrativos naturais, ocorrem 
diversas festas tradicionais oriundas da rica cultura e da peculiar identidade local. Mencionaram ainda que o atual modelo concentra a renda aos donos das propriedades da região, corroborando com o citado pelos pousadeiros e por pescadores locais, que colocam os donos das pousadas e/ou das terras como os detentores do poder local. Os resultados encontrados por Fachin (2002), reforçam estas afirmações ao colocar os habitantes das comunidades tradicionais como dependentes dos recursos oferecidos pelos empresários dos ramos da pecuária e turismo. Dines (1997) ressalta sobre a importância da atividade turística mais democrática e que atue como distribuidora de renda, objetivando a inclusão da comunidade nativa do local ao que se deseja explorar o potencial turístico.

Para que essa mudança aconteça, os entrevistados afirmaram que as autoridades responsáveis, governos federal e estadual, deveriam intervir, criando sistemas reguladores de acesso e passeios, como já acontece em outras cidades com potencial turístico natural. Senra e Silva (2012) apontam que dentre todos os potenciais turísticos do estado de Mato Grosso, uma vertente ainda pouco utilizada e apta a agregar valor ao modelo já estabelecido, são as festas populares, que reforçam a identidade tradicional mato-grossense.

Considerando a identificação dos grupos sociais de Mato Grosso realizada por Sato et al. (2013), os povos pantaneiros, no qual podem ser incluídos os moradores locais nativos da presente pesquisa, são aqueles que apresentam características peculiares de convívio com a dinâmica das águas, revelando saberes locais e trazendo as mais variadas contribuições culturais (comidas, danças, história, lendas, religiosidade, festas); trabalham no agroextrativismo e agricultura familiar. E neste caso, pode ser acrescido ainda, para o Pantanal de Poconé, o trabalho sazonal na atividade turística da região, como constatado no presente trabalho.

\section{Guias de Turismo}

Os quatro guias de turismo entrevistados são profissionais com formação acadêmica na área de biologia, ecologia e/ou ambiental, fluentes em duas ou mais línguas, frequentemente francês, inglês, alemão e espanhol, além dos cursos profissionais obrigatórios. São vinculados, em sua maioria, a agências de turismo internacionais.

Quando solicitado que descrevessem o Pantanal e o pulso de inundação, recorreram a conceitos e termos técnicos, demonstrando percepção com embasamento científico sobre o ambiente, os animais e a dinâmica hidrológica a qual o Pantanal está sujeito. Para Mendonça e Neiman (2002), o profissional do turismo deve atuar como agente de sensibilização ambiental, despertando nos turistas que conduz uma profunda reflexão acerca do meio ambiente, muito além de apenas apreciação da paisagem e para tanto, uma boa qualificação técnica se faz necessária, principalmente, em ecoturismo.

Observou-se nas entrevistas que eles se esforçam para transmitir esse conhecimento aos turistas e afirmam que, pelo menos $95 \%$ dos turistas 
que recebem são estrangeiros, a maioria australianos, alemães e franceses, e que estes possuem profundo desejo de aprender o quanto for possível sobre os animais e o meio ambiente.

Ressaltam ainda a ausência de público brasileiro, que não valoriza este modelo de turismo e não apresentam o mesmo interesse em aprender sobre as interações entre animais, vegetação e pulso de inundação. Com base em sua experiência, afirmam que o turismo não tem causado nenhum dano ao meio ambiente, os turistas estão interessados em contemplar a natureza e conhecer os recursos e, por essa razão, a atividade pode e deve crescer ainda mais.

Apontam que as ameaças a saúde ambiental estão no avanço da agricultura e o aumento do número de hidrelétricas na região do planalto, berço das águas que formam o Pantanal, similar ao mencionado pelos pescadores locais, indicando que estes dois grupos tem maior conhecimento sobre a região e seu entorno em relação aos demais (exceto agente ambientais).

Asseguraram que o turismo nesta região tem se sustentado pela preservação dos recursos, logo é um grande aliado quando desenvolvido de forma sustentável. Entretanto, citam como exceções, a utilização de ceva na observação de onças na região de Porto Jofre e alguns casos de pescado irregular, principalmente fora das medidas permitidas, mas afirmam que ainda assim, até o momento, não existem provas ou punições, devido à baixa frequência de campanhas de fiscalização na região. Sugeriram a regulamentação destas atividades em consonância com a legislação, já que se trata de um recurso sensível.

\section{Agentes de Segurança Ambiental (SEM)}

Os agentes declararam que contam com o apoio e a parceria dos empresários do ramo do turismo na região do Pantanal nas campanhas de inspeção e responsabilização, para denúncias de danos e apoio logístico e infraestrutura. São, portanto, dos empresários, o segmento que mais busca soluções com o órgão ambiental nessa região, através da Associação de Hotéis, Pousadas e Restaurantes, aspecto que não foi mencionado pelos pousadeiros.

As campanhas de fiscalização são constantes, de no mínimo dez dias, fracionadas ao longo do mês. São intensificadas no período de piracema, em que são quinze dias de campo, quando aumenta-se o número de fiscais percorrendo os rios, pois são remanejados para atuar em água. Antes da piracema, todos os empreendimentos que comercializam peixe devem declarar todo estoque de pescado que possuem, bem como a validade e a duração da quantidade declarada. A fiscalização de ninhais ocorre, em média em cinco dias durante quatro meses, dois meses de cheia, dois meses de seca.

Concordaram com o afirmado pelos guias de turismo, ao assegurar que a atividade turística no Pantanal de Poconé tem se amparado na conservação do ecossistema, garantindo a sustentabilidade do ramo nos 
próximos anos. Mencionaram que é necessário que haja uma mudança, em todos os sentidos, da gestão do órgão ambiental, mais pautada atualmente no direcionamento político adotado pelo Estado, e garantem que para tanto, uma das ações prioritárias é a reativação do posto de fiscalização da Transpantaneira, desativado há mais de um ano.

Apesar de serem de coordenadorias diferentes, todos os entrevistados afirmaram enfaticamente que as ações de fiscalização como um todo precisam de maior atenção por parte do governo. Existem regiões dentro do Pantanal onde só é possível chegar por via aérea, sendo que a logística e a falta de recursos e infraestrutura prejudicam o controle dos agentes, sendo que ainda hoje é sabido de crimes ambientais que ocorrem na região. Apesar disso, a população, os empresários locais e também os turistas são peças fundamentais na mitigação dos impactos. Apontaram que apenas a somatória entre leis, fiscalização, educação ambiental e conscientização podem assegurar a qualidade do meio ambiente com suas características naturais e vasta biodiversidade para as gerações futuras, dividindo a responsabilidade de cuidar dos recursos naturais disponíveis no Pantanal entre todos os demais atores sociais. Quando, para os outros grupos, o maior encarregado pela proteção da natureza deve ser o órgão público competente, os agentes destacaram a força de cada um dos envolvidos para atingir os objetivos comuns. Mencionaram ainda a importância dos pousadeiros e guias de turismo como agentes de educação ambiental, a comunidade como agente de fiscalização e os turistas como agentes de proteção, ao passo que adotem posturas em favor do meio ambiente, como não jogar lixo em lugar inadequado, por exemplo.

Reconhecem a dificuldade de abranger toda área do Pantanal, pelo número limitado de recursos humanos e infraestrutura disponível, incluindo equipamentos e recursos financeiros para viabilizar a atividade.

Rodrigues (2013), salienta que "os papéis exercidos pelas esferas pública e privada no turismo em áreas de proteção ambiental podem ser ao mesmo tempo cooperativos e conflitantes", corroborando com o cenário encontrado por esta pesquisa.

\section{Análise do discurso dos atores do turismo}

Ao inserir as transcrições integrais de todas as entrevistas realizadas com os grupos sociais, elencou-se os vinte e cinco termos mais citados (Tabela 3). Entre os vinte e cinco termos, tem-se dois casos especiais: o quarto colocado, a palavra 'Empresa' citado 112 vezes apenas pelos pousadeiros e guias de turismo e o décimo oitavo colocado, a palavra 'Poconé', citada 47 vezes apenas pelos moradores locais, indicando neste caso maior apego à territorialidade do que pelos outros atores sociais. Essas situações corroboram com a discussão anterior, de que a renda do turismo, que tem como local arrecadador as empresas do setor, está centralizada nas mãos de poucas famílias e não retorna em benefício do município de Poconé. 
Tabela 3: Ranking de termos mais utilizados por todos os grupos sociais atuantes na atividade turística do Pantanal de Poconé (MT).

Table 3: Ranking of terms most used by all social groups active in the Pantanal tourist activity of Poconé (MT, Brazil).

\begin{tabular}{|c|c|c|}
\hline Ranking & Termos & $\mathrm{N}^{\circ}$ de citações \\
\hline $1^{\circ}$ & Pantanal & 568 \\
\hline $2^{\circ}$ & Turismo & 230 \\
\hline $3^{\circ}$ & Internet & 123 \\
\hline 4 & Empresa & 112 \\
\hline 5 & Turistas & 85 \\
\hline 6 & Proteção & 79 \\
\hline 7 & Pousada & 73 \\
\hline 8 & Lixo & 67 \\
\hline 9 & Inundação & 66 \\
\hline 10 & Pulso & 62 \\
\hline 11 & Ameaças & 62 \\
\hline 12 & Conservação & 54 \\
\hline 13 & Fiscalização & 52 \\
\hline 14 & Infraestrutura & 52 \\
\hline 15 & Esgoto & 50 \\
\hline 16 & Mudanças & 49 \\
\hline 17 & Futuro & 49 \\
\hline 18 & Poconé & 47 \\
\hline 19 & Tecnologias & 47 \\
\hline 20 & Guias & 45 \\
\hline 21 & Rios & 44 \\
\hline 22 & Ambiental & 44 \\
\hline 23 & Lei & 42 \\
\hline 24 & Publico & 42 \\
\hline 25 & Dinheiro & 39 \\
\hline
\end{tabular}

Desta lista, destacou-se quinze termos que foram citados por todos os grupos pelo menos uma vez, elencados por ordem de repetições (Tabela 4).

O termo 'Pantanal' foi disparadamente o mais utilizado quando analisada todas as entrevistas e todos os grupos (salvo os pescadores), quinhentas e sessenta e oito vezes, por ser o tema principal da abordagem e a área do estudo. O mesmo pode ser dito da palavra turismo e turistas que constituem o subtema principal. Já a palavras pulso e inundação que constituem outro subtema principal vêm após os temas de proteção e de lixo (uma clara ameaça), provavelmente porque para a maior parte dos interlocutores, ela não faz parte do corpus corrente que estes utilizem, salvo no caso dos Agentes de Segurança Ambiental da Secretaria Estadual de Meio Ambiente e pelos Guias de turismo, compreendidos como os detentores de maior capacitação técnica acerca do Pantanal.

Para os grupos dos pousadeiros, dos guias de turismo e dos moradores locais nativos a questão turística (palavras turismo e turista) é evidentemente central e constitui o cerne do seu discurso. No entanto para os moradores, as questões de mudanças e ameaças são mais proeminentes do que para os pousadeiros e guias. Para estes, as questões de conservação e proteção do ambiente natural são imediatamente mais relevantes. 


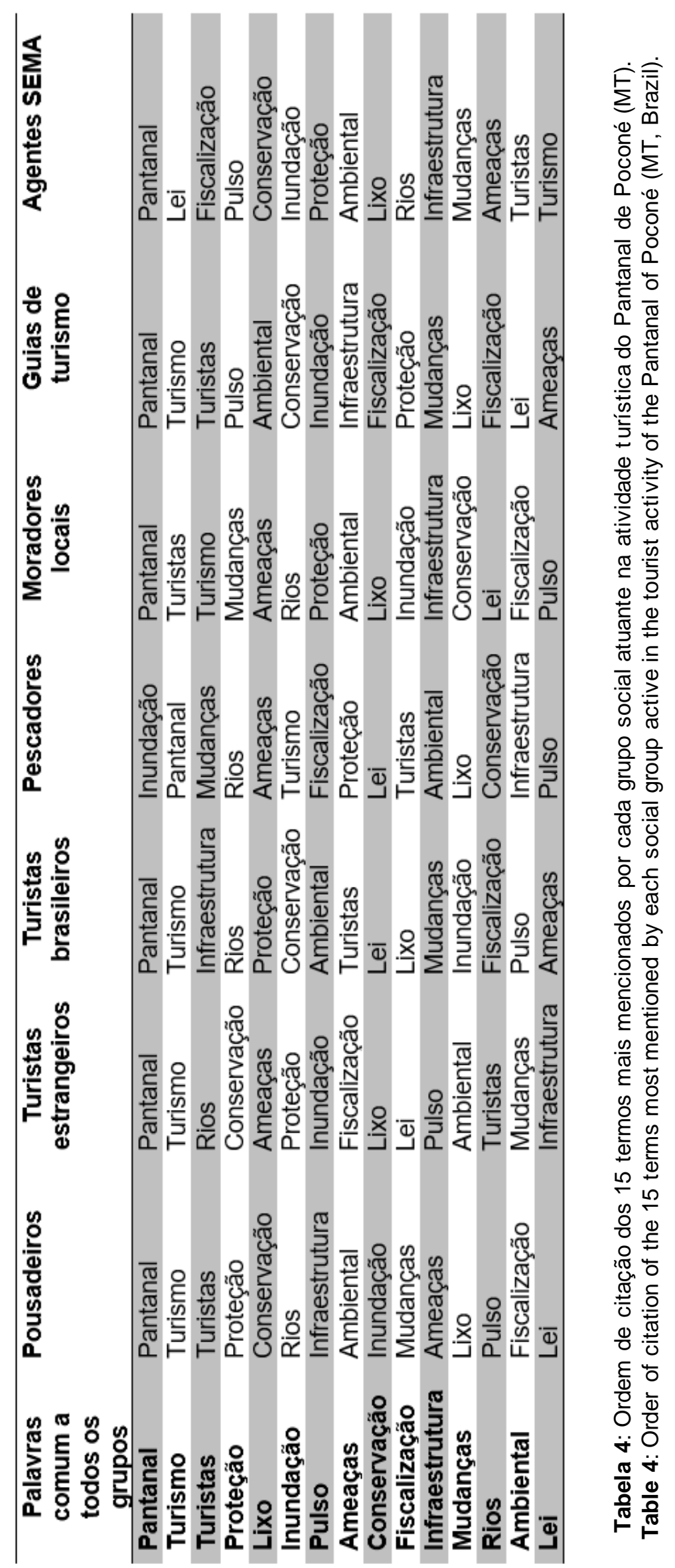


Para os turistas brasileiros as questões de infraestrutura são primordiais enquanto que para os turistas estrangeiros este tema vem de longe depois da preocupação com ameaças (quinta palavra mais mencionada), que é último da lista para os brasileiros.

Os pescadores compõem o grupo que mais detecta as alterações no ambiente, tanto que é o único grupo que menciona o termo inundação mais vezes que a palavra Pantanal. Também a palavra 'mudanças' para este grupo está em posição superior que para outros grupos, seguido somente pelos moradores locais. Os demais grupos, embora citem este termo, não o empregam entre as prioridades de suas colocações. Isso denota que as alterações ambientais que vem ocorrendo no Pantanal afetam mais este grupo, que depende dos recursos naturais diretamente para sua sobrevivência. Este grupo utiliza a palavra fiscalização mais que todo os outros grupos, salvo bem entendido os agentes de segurança ambiental da SEMA para quem constitui o cerne da atividade. Isso reflete, provavelmente, que os pescadores se sentem alvo da fiscalização. Enfim, os pescadores profissionais usam a palavra turismo menos que qualquer outro grupo, salvo os agentes da SEMA, o que pode indicar que a atividade turística para este grupo não é tão relevante. O discurso dos agentes de segurança da SEMA, se distingue também dos demais. Apesar de estar participando de uma pesquisa sobre turismo, as palavras da lista diretamente relacionadas, turistas e turismo, são as menos frequente utilizadas por este grupo. É interessante notar que para os atores diretamente ligados ao turismo, a fiscalização (principal atividade dos agentes) é um tema de menor importância relativa, em décima quarta posição para os pousadeiros, oitavo lugar para os turistas estrangeiros, décimo terceiro lugar para os guias de turismo e turistas brasileiros.

\section{O pulso de inundação e a atividade turística}

O pulso de inundação no Pantanal rege, além de todas as interações biológicas, a presença e intensidade das atividades desenvolvidas por todos os grupos sociais identificados na atividade turística local. O período de seca, compreendido entre os meses de maio e setembro, é a alta temporada do turismo nessa região, quando a pesca está liberada, atraindo pescadores amadores e profissionais e também turistas estrangeiros atraídos pela enorme quantidade de animais dispersos pela planície seca. A fiscalização dos agentes da Secretaria Estadual de Meio Ambiente permanece, porém é menos intensificada que na cheia, que corresponde ao período de reprodução dos peixes. As atividades dos moradores locais nativos permanecem ao longo do ano. O homem pantaneiro tem suas atividades regidas pelo ciclo das águas para cada tipo de atividade que exerce ao longo do ano, mantendo-se no local independente do período seco ou chuvoso, visto que não há êxodo em razão da época hidrológica, como ocorre, por exemplo, com o grupo dos guias de turismo e com os turistas, especialmente àqueles voltados à atividade de pesca. 
Para os diversos grupos entrevistados o grau de importância do fenômeno do pulso de inundação varia. Para os pescadores profissionais, cujo atividade depende do comportamento dos estoques de peixes comerciais, o pulso é fundamento para a manutenção da própria atividade e sobrevivência direta. Para os moradores do Pantanal, o pulso é crucial para a manutenção do estilo de vida. Para os pousadeiros, muitos atrativos turísticos e as modalidades de operação do negócio deles dependem do pulso. A realidade dos guias de turismos, cuja atividade é em grande parte ligada aos pousadeiros, é similar. Os turistas brasileiros e estrangeiros estão também condicionados tanto pelos guias e pousadeiros quanto pelo pulso. Enfim, os agentes da SEMA exercem a sua atividade em função da atividade dos outros atores mencionados. Assim o grau de importância "real" do pulso para estes grupos pode ser assim expressa:

Pescadores $>$ moradores $>$ pousadeiros $>$ guias $>$ turistas $>$ agentes SEMA

No entanto, a importância relativa do pulso declarada por cada grupo de informante difere da importância "real". A frequência de uso da palavra "inundação" no discurso de cada um dos grupos dá uma indicação da importância que cada grupo atribua ao fenômeno do pulso de inundação para atividade turística. Da mesma forma, a frequência do uso da palavra "pulso", que é mais técnica, informa sobre a familiaridade que cada grupo têm com o aspecto técnico-cientifico do pulso.

As relações entre importância "real", importância atribuída e familiaridade com conceito de pulso de inundação em ligação a atividade turística é revelada pelas Figuras 2a) e 2b). Quando se compara a importância "real" do pulso com importância atribuída, verifica-se que os pousadeiros e turistas brasileiros não atribuem importância condizente com a realidade, diferentemente dos pescadores, que atribuem importância a inundação em função da importância real que tem para eles (2a). Ao contrário, a familiaridade com conceito de pulso é menor para quem este é mais importante na realidade: os pescadores, os moradores locais e os pousadeiros (2b).

Silva (1992) afirma que as comunidades tradicionais são um patrimônio cultural e que estão envolvidos em todos os setores da economia local, inclusive no turismo. Porém, poderiam ser melhor aproveitados se mais ativos na gestão das atividades econômicas, especialmente o turismo. Os resultados indicam que nem todos os atores tradicionais (pescadores e moradores) têm a mesma percepção da importância do pulso de inundação e que, em todo caso, têm pouco domínio do conceito técnico, domínio que sem dúvida faz falta para inserir-se de fato na gestão da economia regional. No caso específico, dos principais agentes econômicos do turismos, os pousadeiros e os guias, os resultados indicam que os primeiros ainda não se deram conta da primazia do pulso de inundação para sua atividade. Enfim, o discurso dos fiscais do sistema, os agentes da SEMA, revela que atribuem grande importância relativa a inundação e dominam o conceito de pulso. 


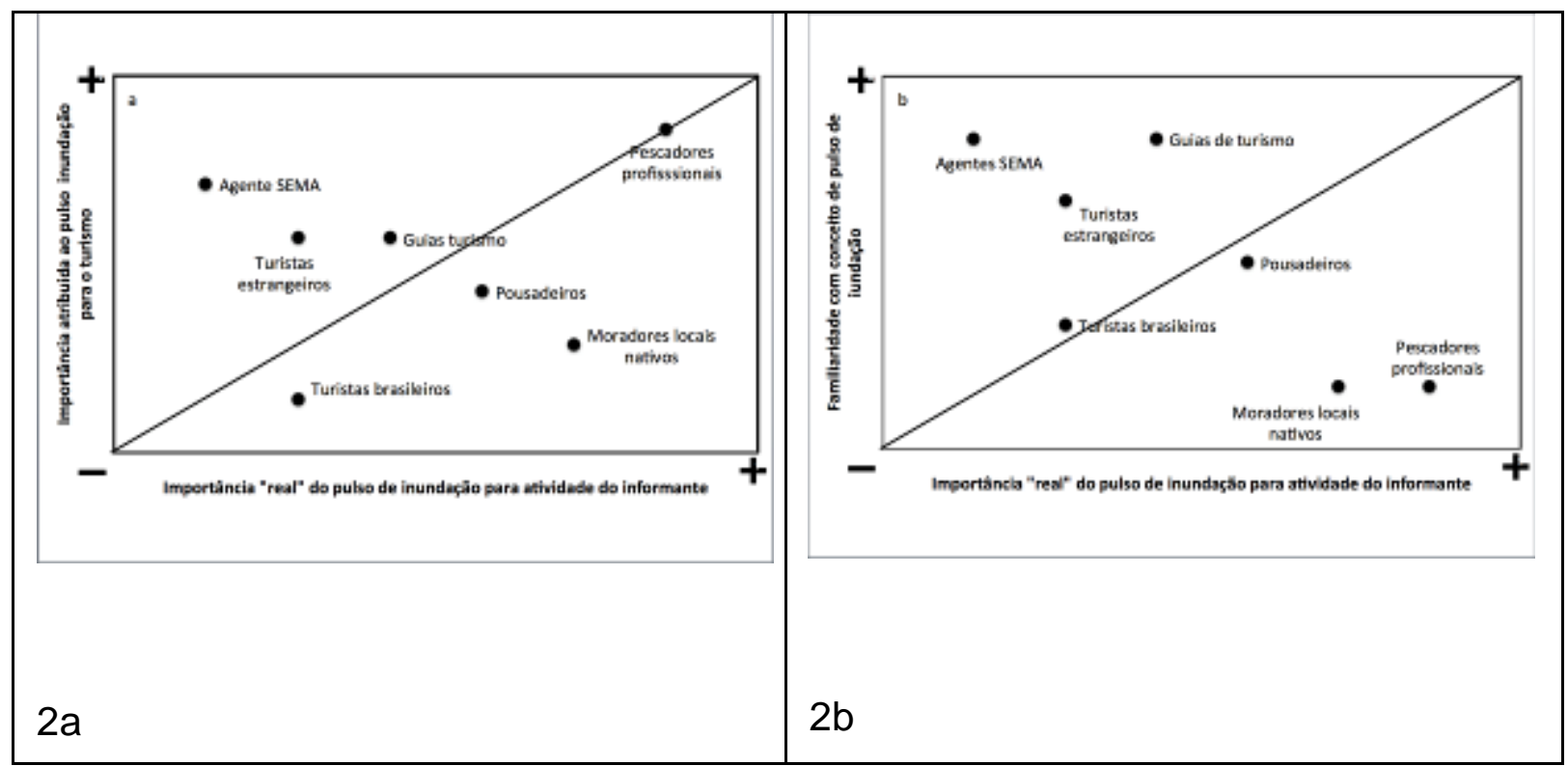

Figura 2: Importância "real" do pulso de inundação para cada grupo em relação à importância atribuída a inundação para atividade turística e a familiaridade com conceito de pulso de inundação pelos atores sociais da atividade turística no Pantanal de Poconé (MT).

a) importância "real" e importância atribuída. b) importância "real" e familiaridade com conceito de pulso.

Figure 2: The "real" importance of the flood pulse for each group in relation to the importance attributed to the flood for tourist activity and the familiarity with the concept of flood pulse by the social actors of the tourist activity in the Pantanal of Poconé (MT, Brazil). A) "real" importance and importance assigned. B) "real" importance and familiarity with the concept of pulse.

\section{Conclusões}

A metodologia aplicada permitiu identificar sete grupos sociais envolvidos na atividade turística do Pantanal de Poconé, ao longo das rodovias Transpantaneira e Porto Cercado, e registrar a percepção destes grupos sociais sobre o meio ambiente, especificamente o pulso de inundação. A identificação dos principais atores sociais participantes, direta ou indiretamente, da atividade turística indicou a necessidade de haver um processo mais participativo, inclusivo e educacional, tanto no planejamento quanto na gestão dos recursos utilizados atualmente e dos potenciais, neste caso referindo-se ao aproveitamento dos atrativos da época de cheia. Observou-se que, entre os atores sociais do turismo no Pantanal, há necessidade de maior colaboração entre eles, visando, em primeiro lugar, a sustentabilidade ambiental e econômica desta atividade. As respostas dos atores sociais sobre a gestão da atividade turística demonstraram a necessidade de um planejamento e gestão mais participativa que incorpore todos os interesses da sociedade.

Este estudo permitiu identificar os seguintes conflitos: i) entre pecuaristas e pousadeiros, no que diz respeito à onça pintada, sendo que para os primeiros esta espécie representa prejuízos ao rebanho e aos pousadeiros uma fonte de renda quanto ao turismo de "observação de onça"; ii) entre a população nativa, tanto os moradores locais quanto os 
pescadores profissionais, que almejam por participarem mais diretamente no turismo e das instâncias de poder, concentrada nos pousadeiros e/ou pecuaristas, considerando os saberes que possuem e a forte conexão com o ambiente pantaneiro; iii) ao aumento da dificuldade de acesso ao pescado pelos pescadores profissionais nativos, devido às atividades antrópicas nas partes altas da bacia.

O pulso de inundação exerce forte influência sobre o aproveitamento turístico do Pantanal de Poconé, pois rege o ciclo de vida e a reprodução de diversas espécies animais que são os principais atrativos aos turistas. Entretanto, não é nitidamente compreendido pelos principais grupos sociais atores da atividade turística, tanto quanto a percepção da importância do pulso na sua atividade quanto ao entendimento do conceito em si. Os grupos com melhor capacitação técnica (guias de turismo e agentes ambientais) apresentaram melhor compreensão destes dois aspectos investigados sobre o pulso de inundação. Os pescadores profissionais, mesmo que não dominando o conceito de pulso atribuam a devida importância ao fenômeno do pulso de inundação.

O estudo apontou ainda a importância de se desenvolver um turismo com maior identidade local, que incluam outros atrativos, como as festas tradicionais da rica cultura de Poconé e a diversidade de ecossistemas aquáticos e terrestres na época de cheia.

\section{Referências}

ALEXA, M. Computer-assisted text analysis methodology in the social sciences. Zentrum fur Umfragen Methoden und Analysen - ZUMA - (Ed.).: Mannheim, 1997

ANA-AGÊNCIA NACIONAL DE ÁGUAS. Bacias Hidrográficas. Disponível em: http://www2.ana.gov.br/Paginas/portais/bacias/default.aspx. Acesso em: 10 de maio de 2017.

BRASIL. Ministério do Interior. Estudo de desenvolvimento integrado da bacia do Alto Paraguai: Relatório da 1a fase, descrição física e recursos naturais. Brasília: SUDECO/EDIBAP, t.2, 235p.1979.

BRASIL. Ministério do Meio Ambiente. Secretaria de Biodiversidade e Florestas. Política Nacional de Biodiversidade: Roteiro para consulta para elaboração de uma proposta. Brasilia: MMA/SBF, 32p. 2000b.

BRITO, M.A.; SOBREVILA, J.C. DALPONTE; G.A. BORGES, C. Sem data. Setting conservation priorities in the state of Mato Grosso, Brasil. Relatório ao Centro de Dados para Conservação, Fundação Estadual de Meio Ambiente, Cuiabá, Brasil.

CCTP- Coordenação das comunidades tradicionais do Pantanal. Disponível em: <http://riosvivos.org.br/pantanal/desenvolvimento-integral-decomunidades-/coordenac\%CC\%A7a\%CC\%83o-das-comunidadestradicionais-do-pantanal-cctp/> Acesso em: 01/09/2016. 
CHAVES, P.T; FREIRE, K.M.F. A pesca esportiva e o pesque-e-solte: pesquisas recentes e recomendações para estudos no Brasil. Bioikos, Campinas, 26(1):29-34, jan./jun., 2012.

CUNHA, C.N.; JUNK, W.J. Landscape units onf the Pantanal: strusture, function and human use. In: In: JUNK, W.J.; DA SILVA, C.J.; CUNHA, C.N.; WANTZEN, K.M. The Pantanal. Ecology, biodiversity and sustainable mamagement of a large neotropical seasonal wetland. Sofia-Moscow: Pensoft, 2011. 301-326 p.

DA SILVA, C.J. Influência da variação do nível da água sobre a estrutura e funcionamento de uma área alagável do Pantanal Mato-grossense (Pantanal de Barão de Melgaço, Município de Santo Antônio de Leveger e Barão de Melgaço - MT). São Carlos. Tese (Doutorado). Universidade Federal de São Carlos, Departamento de Ciências Biológicas, 1990.

DA SILVA, C.J.; SILVA, J.A.F. No ritmo das águas do Pantanal. São Paulo: NUPAUB/USP, 1995.

DA SILVA , J.S.V.; ABDON, M.M. Delimitação do Pantanal brasileiro e suas sub-regiões. Pesq. agropec. bras., Brasilia, v.33, Número Especial, p.1703-1711, out. 1998.

DARWALL, W.; SMITH, K.; ALLEN, D. SEDDON, M.; MCGREGOR REID, G. CLAUSNITZER, V.; KALKMAN, V. Freshwater biodiversity - a hidden resource under threat. In: VIÉ, J-C., HILTON-TYLOR, C.; STUARD, S.N. 2008.

DINES, M. Turismo em Parques: análise e perspectivas para o ecoturismo no Núcleo Santa Virgínia - Parque Estadual da Serra do Mar - São Paulo. Anais do Congresso Brasileiro de Unidades de Conservação, Curitiba:IAP/Unilivre/Rede Pro Unidades de Conservação, p.307-319; 1997.

FACHIM, E. Bases para a Elaboração do Plano de Manejo Participativo de uma Unidade de Conservação Estadual: A Estrada Parque Transpantaneira, Poconé - Mato Grosso. Cuiabá, Dissertação (Mestrado) - Instituto de Biociências, Universidade Federal de Mato Grosso. 78p. 2002.

FIGUEIREDO, D.M.; SALOMÃO, F.X.T. Bacia do rio Cuiabá. In: FIGUEIREDO, D.M.; SALOMÃO, F.X.T. Bacia do rio Cuiabá: uma abordagem socioambiental. Cuiabá: Entrelinhas-EdUFMT, 2009. 41-45 p.

GIRARD, P. Efeito cumulativo das barragens no Pantanal. Campo Grande/ MS. Instituto Centro Vida. 28 p. 2002.

GIRARD, P. Hydrology of surface and ground waters in the Pantanal floodplains. In: W. J. JUNK; C. J. DA SILVA; C. NUNES DA CUNHA; K. M. WANTZEN. (Org.). The Pantanal: Ecology, biodiversity and sustainable manegement of a large neotropical seasonal wetland. Sofia: Pensoft Publishers, 2011, v., p. 103-126.

GIRARD, P. The Pantaneiros, Perceptions and conflicts about the Environment in the Pantanal. In: IORIS, A.R. (Org.). Tropical Wetland Management: The South-American Pantanal and the International Experience. Surrey, London: Ashgate Publishing, p. 7-27. 2012. 
GIRARD, P.; VARGAS, I. Turismo, desenvolvimento e saberes no Pantanal: diálogos e parcerias possíveis. Desenvolvimento e Meio Ambiente, Ed. UFPR, n. 18, p. 61-76, 2008.

HARRIS, M.B.; TOMAS, W. M.; MOURÃO, G.; DA SILVA, C.J.; GUIMRÃES, E.; FACHIM, E. Desafios para proteger o Pantanal brasileiro: ameaças e iniciativas em conservação. Megadiversidade, v.1. ํㅜ 1. 2005.

JUNK, W.J.; BAYLEY, P.B.; SPARKS, R.E. The flood pulse conceptin river floodplain. Can. Spec. Publ. Fih. Aquat. Sci., (106): 110-127, 1989.

JUNK, W.J. Structure and function of the large Central-Amazonian riverfloodplains: synthesis and discussion. In: JUNK, W.J. (Ed.). The Central Amazon Floodplain: ecology of a pulsing system. Berlin: Springer Verlag, (Ecological Studies, 126) p. 455-472, 1997.

JUNK, W.J.; CUNHA, C.N.; DA SILVA, C.J.; WANTZEN, K.M. The Pantanal: A large South American wetland and its position in limnological theory. In: JUNK, W.J.; DA SILVA, C.J.; CUNHA, C.N.; WANTZEN, K.M. The Pantanal. Ecology, biodiversity and sustainable mamagement of a large neotropical seasonal wetland. Sofia-Moscow: Pensoft, 2011. 23-44 p.

JIMÉNEZ-RUEDA, JR.; PESSOTTI, J.E.S.; TAVARES DE MATOS, J. Modelo para o estudo da dinâmica evolutiva dos aspectos fisiográficos dos pantanais. Pesquisa Agropecuária Brasileira, 33(n.esp): 1763-1773, 1998.

JUNK, W. J.; M. T. F. Piedade; R. Lourival; F.Wittmann; P. Kandus; L. D. Lacerda; R. L. Bozelli, F. A. Esteves, et al. 2014. Brazilian wetlands: their definition, delineation, and classification for research, sustainable manegement and protection. Aquatic Conservation Marine and Freshwater Ecosustems v.24, p.5-22.

MARCONI, M.A.; LAKATOS, E.M. Técnicas de Pesquisa: planejamento e execução de pesquisas, amostragens e técnicas de pesquisa, elaboração, análise e interpretação de dados. 7 ed. - São Paulo : Atlas, 2012.

MENDONÇA, R., NEIMAN, Z. Ecoturismo: Discurso, Desejo e Realidade. In: NEIMAN, Z. (org.). Meio Ambiente, Educação e Ecoturismo. 1. ed. Barueri, SP: Manole, 2002.

MILLENIUM ECOSSISTEM ASSESSMENT. Ecosystems and human wellbeing: wetlands and water, 2005. Disponível em : <http://www.unep.org/maweb/documents/document.358.aspx.pdfMillennium>

MORAES, A.S. Impactos da pesca na Estrada Parque Pantanal. Corumbá, MS: Embrapa Pantanal; Brasilia: WWF, 128 p. 2002.

NUNES DA CUNHA, C.; JUNK, W.J. (2011): Landscape units of the Pantanal: their structures, functions and human use. In: JUNK, W.J.; DA SILVA, C.J.; NUNES DA CUNHA, C.; WANTZEN, K.M. (Eds.). The Pantanal: Ecology, biodiversity and sustainable management of a large neotropical seasonal wetland. Sofia-Moscou: PENSOFT Publishers, 2011.

LODI, JOÃO BOSCO. A entrevista: teoria e prática. 1. ed. - São Paulo, 1977. 
RAMSAR. The convention on wetlands. Disponível em:<www.ramsar.org $>$. Acesso em: 12 ago. 2016.

RAMSAR. UNWTO. Destination wetlands: supporting sustainable tourism. Madrid, Spain. 2012.

REBELLATO, L. Padrões sazonais e espaciais de distribuição e diversidade de herbáceas no Pantanal de Poconé-MT. Belo Horizonte/MG: UFMG, Tese (Doutorado) - instituto de ciências biológicas - Pós-graduação em ecologia, conservação e manejo da vida Silvestre. 162 f. 2010.

RESENDE, E.K. Pulso de Inundação: Processo Ecológico Essencial à Vida no Pantanal. Corumbá: Embrapa Pantanal, (Documentos / Embrapa Pantanal, ISSN 1981-7223; 94). 16p. 2008.

RODRIGUES, C.G.O; GODOY, L.R.C. Atuação pública e privada na gestão de Unidades de Conservação: aspectos socioeconômicos da prestação de serviços de apoio à visitação em parques nacionais. Revista Desenvolvimento e Meio Ambiente, v. 28, p. 75-88, jul./dez. 2013.

SATO, M.; JABER, M.; SILVA, R.; QUADROS, I.; ALVES, M.L. Mapeando os territórios e identidades do Estado de Mato Grosso, Brasil. Cuiabá: Fapemat/EdUFMT/Governo de Mato Grosso, 2013. 205 p.

SENRA E SILVA, J. F. A Identidade tradicional mato-grossense expressa no Siriri Cururu e São Gonçalo: uma intersubjetividade cultural e seu devir. Cáceres/MT: UNEMAT - Universidade Estadual de Mato Grosso. Dissertação (Mestrado) - Universidade do Estado de Mato Grosso. Programa de Pós-Graduação em Educação, 123 f, 2012.

SERAFINI, L.Z. Proteção jurídica das áreas úmidas e os direitos socioambientais. Dissertação (Mestrado em Direito) - Pontifícia Universidade Católica do Paraná, Curitiba, 2007.

SILVA, C; SILVA J. 1992. Estratégias de sobrevivência de comunidades tradicionais no Pantanal Matogrossense. São Paulo, NUPAUB-USP.

SILVA, J.S.V.; ABDON, M.M. Delimitação do Pantanal brasileiro e suas subregiões. Brasília: Pesquisa Agropecuária Brasileira, v. 33, Número Especial: 1703-1711. 1998.

SCBD: Global biodiversity outlook 3. - Secretariat of the Convention on Biodiversity. Montreal, Canada. 2010

SINCLAIR, S.; ROCKWELL, G. Teaching computer-assisted text analysis. Digital Humanities Pedagogy: Practices, Principles and Politics. Brett D. Hirch. ed. Open Book Publishers. 2012.

SINCLAIR, S.; ROCKWELL, G. Text Analysis and Visualizatio". In: SCHEIBMAN, S.; SIEMENS, R.; UNSWORTH, J. (ed.). A New Companion to Digital Humanities. John Wiley \& Sons. Ltd. Chicherster. U.K. 2015 
SOUZA, C. F.; COLLISCHONN, W; TUCCI, C. E. M.; ARTHINGTON, A. H. Preliminary assessment of dam hydrological effects in the Brazilian Pantanal. In: Program \& Abstracts Book of 2009 International Symposium on Ecohydraulics. The Internatonal Conference of Science and Information Technologies for Sustainable Manegement of Aquatic Ecosystems Concepción. Chile. 11p. 2009.

SUDRÉ, S.G.S. Caracterização do turismo dos barcos-hotéis de Cáceres, no rio Paraguai, Pantanal Mato-Grossense, Brasil. 2012. p. 19-72. Dissertação (Mestrado) Programa de Pós Graduação em Ciências Ambientais Universidade do Estado de Mato Grosso, Cáceres/MT, 2012.

SPAOLONSE, E.; MARTINS, S.S.O. Ecoturismo: uma ponte para o turismo sustentável. Revista Brasileira de Ecoturismo, São Paulo, v.9, n.6, nov2016/jan-2017, p. 684-698.

TARIFA, J. R. Mato Grosso: Clima, Análise e Representação cartográfica. Cuiabá: Entrelinhas, 2011. (Série Recursos Naturais e Estudos Ambientais). $102 \mathrm{p}$.

WANTZEN, K.M.; DA CUNHA, C.N.; JUNK, W. J.; GIRARD, P.; ROSSETTO, O. C.; PENHA, J. M.; COUTO, E. G.; BECKER, M.; PRIANTE, G.; TOMAS, W. M.; SANTOS, S. A.; MARTA, J.; DOMINGOS, I.; SONODA, F.; CURVO, M.; CALLIL, C. Towards a sustainable manegement concept for ecosystem services of the Pantanal Wetland. Ecohydrology \& Hydrobiology, v. 8, p. 115-138, 2008.

WCD - WORLD COMMISSION ON DAMS. Dams and development. A new framework for decision-making. The report of the World Commission on Dams. Earthscan Publications. Ltd, London and Sterling, London, United Kingdom, VA. 404 pp.

\section{Notas:}

i Este trabalho faz parte do projeto "Digital conservation in the Pantanal Developing new political ecology perspectives on digital applications in natural resource conservation" vinculado a programas de pós-graduação no Brasil - gerido exclusivamente pela CAPES através do programa Ciência Sem Fronteiras e foi desenvolvido como dissertação de mestrado pela primeira autora, no Programa de Pós-Graduação em Recursos Hídricos da Univ. Federal de Mato Grosso.

ii Os autores agradecem a CAPES pelo fomento no desenvolvimento deste trabalho e a todos os entrevistados atores do turismo no Pantanal.

lii Os autores agradecem à CAPES pelas bolsas de mestrado e pósdoutorado (PNPD).

iii Os autores agradecem a CAPES pela concessão das bolsas de mestrado e pós- 
Maiara Thaisa Oliveira Rabelo: Universidade Federal do Mato Grosso, Cuiabá, MT, Brasil.

E-mail: tha.rabelo@hotmail.com

Link para o currículo Lattes: http://lattes.cnpq.br/4119967882764916

Koen Antonius Johannes Arts: Universidade Federal do Mato Grosso, Cuiabá, MT, Brasil.

E-mail: koen.arts@wur.nl

Link para o currículo Lattes: http://lattes.cnpq.br/5153223843037279

Pierre Girard: Universidade Federal do Mato Grosso, Cuiabá, MT, Brasil.

E-mail: pierregirard1301@gmail.com

Link para o currículo Lattes: http://lattes.cnpq.br/0442161398765567

Antonio Augusto Rossotto loris: Escola de Geografia e Planejamento,

Cardiff University, UK

E-mail: lorisA@cardiff.ac.uk

Link para página eletrônica: https://www.cardiff.ac.uk/people/view/522826-

ioris-antonio

Daniela Maimoni de Figueiredo: Universidade Federal do Mato Grosso, Cuiabá, MT, Brasil.

E-mail: dani_figueiredo@uol.com.br

Link para o currículo Lattes: http://lattes.cnpq.br/3560534707014049

Data de submissão: 26 de maio de 2017

Data de recebimento de correções: 14 de junho de 2017

Data do aceite: 14 de junho de 2017

Avaliado anonimamente 